\title{
Identification of Polymorphisms in CAST Gene Associated with Economic Traits in Hanwoo (Bos taurus coreanae)
}

\author{
Jae-Don Oh, Jin-A Lee, Kun-Woo Lee, Kyung-Do Park, Byung-Wook Cho', Gwang-Joo Jeon, \\ Hak-Kyo Lee and Hong-Sik Kong*
}

Genomic Informatics Center, Hankyong National University, Anseong, 456-749, Korea

${ }^{1}$ School of Bio-Resources, Pusan National University, Busan, 627-706, Korea

Received July 8, 2010 / Accepted October 18, 2010

\begin{abstract}
A number of studies have shown that the calpain system is important in normal skeletal muscle growth. An increased rate of skeletal muscle growth can result from a decreased rate of muscle protein degradation, and this is associated with a decrease in activity of the calpain system, due principally to a large increase in calpastatin (CAST) activity. The CAST gene, mapped to BTA 7, is considered a candidate gene for beef tenderness and muscle growth. The present study used comparative sequencing of five novel polymorphisms located within exon 20 and 22 of the bovine CAST gene in Hanwoo: exon20- 109737G/A, 109749T/C, 109823T/C, exon22- 116151G/A, intron- 109926G/A. The association of the CAST SNPs with economic traits was studied. The 109926G/A showed a significant effect only on the longissimus muscle area (LMA, p<0.05) in Hanwoo. 109926G/A with the genotype GG had a significantly higher effect on LMA (75.35) than the genotype AA (69.6, p<0.05). Also, the 116151G/A showed a significant effect only on weight at 18 months (W18, $\mathrm{p}<0.05)$. 116151G/A with the genotype GG had a significantly higher effect on W18 (428.54) than the genotype AA $(408.87, \mathrm{p}<0.05)$.
\end{abstract}

Key words : Calpastatin, CAST gene, SNP, Hanwoo

\section{서 론}

다형성을 이용한 유전적 표지(genetic marker)의 분석 기술 의 발전은 중요한 경제형질을 결정하는 주요유전자와 양적 형질 좌위(quantitative trait loci, QTL), 연관 분석(linkage analysis), 유전자 지도작성(genetic mapping), 품종간의 구별 (distinction of breeds), 친자 감별(parentage testing), 가계도 분석(pedigree analysis) 및 연관성(relationship) 등의 분석을 가능하게 하였다. 또한, 주유전자(major gene) 혹은 양적 형질 유전자 좌위에 연관되어 있는 유전적 표지를 이용하여 가축의 유전 및 육종 분야에서는 도움 선발(marker assisted selection, $\mathrm{MAS}$ )에 활용하고 있다. 가축의 대부분의 경제형질은 다양한 유전자들의 상호작용을 통하여 발현되고 있어 이러한 형질에 관여하는 유전자의 탐색과 이들간의 상호작용에 대한 연구가 활발하게 진행되고 있다. 형질과 관련된 기능유전자를 대상으 로 단일 염기 다형성(single nucleotide polymorphism, SNP) 발굴과 형질과의 연관성 분석을 통한 유전자 마커를 개발하기 위한 연구가 활발히 진행 중에 있다. 최근 LPL 유전자[25] TCAP 유전자[4], DIGAT1 유전자[21], FABP 유전자[5] 그리고 $M C 4 R$ 유전자[15] 등 다양한 형질관련 유전자의 SNP 발굴이 국내 연구진을 통해 보고되고 있다.

\section{*Corresponding author}

Tel : +82-31-670-5330, Fax : +82-31-675-5331

E-mail : kebinkhs@empal.com
Calpain은 cystein protease를 암호화하고 postmortem tenderization 시 첫 번째 효소 역할을 하여 Warner Bratzler Shear Force (WBSF) scores를 줄여 고기의 연도에 영향을 주는 유전자로 알려져 있으며[13,20] 도축 후 도체의 단백질을 분해 하여 육질이 부드러워 질 수 있도록 하는데 중요한 역할을 하는 것으로 보고되었다. Calpastatin (CAST)은 calpain의 억 제제(endogenous inhibitor) 역할을 하는 유전자이며 BTA7에 위치하고 있다[3]. Calpain을 억제하는 CAST 유전자 내 다형 성이 육질의 연도에 영향을 미치고 있는 것이 여러 연구를 통해 보고된 바 있다[3,6-8,26,28]. 또한 $\mathrm{Ca}^{2}+$ 농도 의존적으로 활성화되는 neutral protease calpain에 의한 단백질 분해는 세포의 성장을 조절하는 중요한 단백질들에 매우 중요한 영향 을 미치게 된다. 여러 연구를 통해 calpain 시스템은 일반 골격 근의 성장에 중요한 역할을 하는 것으로 보고되었다[1,2,27]. 따라서 본 연구는 한우(Bos taurus coreanae) 집단의 CAST 유전 자 내 변이 지역을 탐색하여 경제형질과의 연관성을 분석하기 위하여 실시하였다.

\section{재료 및 방법}

\section{공시재료 및 DNA 추출}

공시재료로 도체 및 성장관련 성적(생체중, 도체중, 도체율, 배장근 단면적, 등지방 두께, 근 내 지방도, 6 개월령, 12 개월령, 18 개월령, 24 개월령 체중)을 보유한 한우 후대 검정 우 191 두 
의 혈액을 EDTA가 첨가된 튜브에 채취한 후 AccuPrep ${ }^{\circledR}$ Genomic DNA Extraction Kit (BioNEER, Korea)을 이용하여 $\mathrm{DNA}$ 를 추출하여 본 연구에 활용하였다.

\section{PCR 수행 및 Sequencing 수행}

소의 CAST 유전자 염기서열 정보(Gene bank accession no. NC_007305)를 바탕으로 31개의 exon 지역을 대상으로 한 총 8 종의 primer를 제작하여 $\mathrm{PCR}$ 증폭을 위한 조건을 설정하였 다(Table 1).

PCR 반응 액은 Template DNA 20 100 ng/ $\mathrm{ll}$, 각각의 primer 쌍 $0.1 \mu \mathrm{l}(10 \mathrm{pmol}), 10$ X Buffer $1.2 \mu \mathrm{l}(10 \mathrm{mM}$ Tris-HCl, $50 \mathrm{mM} \mathrm{KCl}, 1.5 \mathrm{mM} \mathrm{MgCl} 2, \mathrm{pH} 8.3)$, dNTP 1 l (2.5 mM), Taq polymerase $0.06 \mu \mathrm{l}(10 \mathrm{unit} / \mu \mathrm{ll})$ (Genetbio, Korea)를 첨가 한 후 PCR 반응 액을 총 $10 \mu \mathrm{l}$ 으로 조성하였다. 반응조건은 최초 $95^{\circ} \mathrm{C}$ 서 10 분간 예비가열 한 후 $95^{\circ} \mathrm{C}$ 에서 30 초 동안 변성 시키고, 각 primer에 대응하는 annealing 온도(Table 1)에서 30 초 그리고 $72^{\circ} \mathrm{C}$ 서 40 초 합성시키는 총 35 사이클을 반복 수행하고 $72^{\circ} \mathrm{C}$ 서 10 분간 마지막 합성단계를 수행하고 DNA 증폭을 중단하였다. 증폭된 산물은 $2 \%$ agarose gel에서 전기 영동을 실시하여 각 primer별 증폭산물의 크기를 확인하였다.

증폭된 CAST 유전자의 증폭 산물은 purification 과정을 통 해 주요 증폭 산물 외의 band들을 제거한 후, $\mathrm{BigDye}^{\circledR}$ Terminator v3.1 Cycle Sequencing Kits (Applied Biosystems, $\mathrm{USA}$ )를 이용하여 각각의 염기에 형광 dye를 부착 한 후, $\mathrm{ABI}$ 3130 Genetic Analyzer (Applied Biosystems, USA)를 통하여 각 primer에 대한 개체 별 염기서열을 결정하였다. 결정된 염 기서열은 seqMAN ㅍ (DAN SATAR Inc.) 프로그램을 이용하

Table 1. PCR primers information for identification of polymorphisms in bovine CAST gene

\begin{tabular}{|c|c|c|}
\hline Primer name & Primer sequences $\left(5^{\prime}-3^{\prime}\right)$ & Annealing TM $\left({ }^{\circ} \mathrm{C}\right)$ \\
\hline CAST_1 & $\begin{array}{l}\text { agccaaaaagcctacccaag } \\
\text { agacctgggttcactccctg }\end{array}$ & $65^{\circ} \mathrm{C}$ \\
\hline CAST_2 & $\begin{array}{l}\text { cgtagtggtagctgcagaggtt } \\
\text { ctgagtttccagctcctccc }\end{array}$ & $65^{\circ} \mathrm{C}$ \\
\hline CAST_3 & $\begin{array}{l}\text { agtgccagctcacaaattgc } \\
\text { tttatttggggagttggggt }\end{array}$ & $65^{\circ} \mathrm{C}$ \\
\hline CAST_4 & $\begin{array}{l}\text { agtctcatgttgtccacccg } \\
\text { tcccaggtctgttccatgtc }\end{array}$ & $65^{\circ} \mathrm{C}$ \\
\hline CAST_5 & $\begin{array}{l}\text { cattgggcacatgtctcctc } \\
\text { aacccaacttccattaagcca }\end{array}$ & $65^{\circ} \mathrm{C}$ \\
\hline CAST_6 & $\begin{array}{l}\text { catggcttgatctctgccac } \\
\text { gcttgcctcctacccatta }\end{array}$ & $65^{\circ} \mathrm{C}$ \\
\hline CAST_7 & $\begin{array}{c}\text { tttggaattcctgctttcagag } \\
\text { caaaaggcatattcagagaacctt }\end{array}$ & $65^{\circ} \mathrm{C}$ \\
\hline CAST_8 & $\begin{array}{l}\text { ttgacattgacagatgtgtttgc } \\
\text { ttttccgtttggtcacctg }\end{array}$ & $65^{\circ} \mathrm{C}$ \\
\hline
\end{tabular}

여 개체 간 변이여부를 확인하였다.

\section{통계분석}

연관불균형 분석

연관불균형(Linkage disequilibrium) 정도를 측정하기 SNPAnalyzer 2.0 (Istech, Korea)를 사용하여 변이간의 D'와 $\mathrm{r}^{2}$ 값을 추정하였다.

\section{형질과의 연관성 분석}

한우의 CAST 유전자 내 변이와 경제형질간의 연관성을 분 석하기 위해 SAS Package (Version 9.1)를 사용하였으며 통계 분석이 이용된 모형은 아래와 같다.

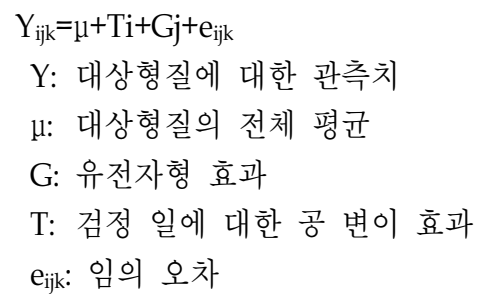

\section{결과 및 고찰}

\section{$C A S T$ 유전자 내 변이지역 탐색 및 유전자형 분석}

본 연구에서 이용된 CAST 유전자(Accession no. NC_007305) 31 개의 exon 지역을 대상으로 단일염기변이지역을 탐색 결과 exon 20번 지역에서 3개의 변이(109737G/A, 109749T/C, $109823 \mathrm{~T} / \mathrm{C}$ )를 탐색하였고, exon 22번 지역에서 하나의 변이 (116151G/A)를 탐색하였으며, exon 20번 뒤쪽에 위치한 intron 지역에서 한 개의 변이(109926G/A)를 탐색하였다(Fig. 1). 또한 탐색된 5개의 변이(109749T/C, 116151G/A, 109737G/A, 109823T/C, 109926G/A)는 기존의 NCBI에 등록되어 있지 않 은 새로운 변이로 본 연구를 통해 탐색되었다(Table 2). Exon 지역에서 발견된 변이 중 3개의 변이(109749T/C, 116151G/A, $109926 \mathrm{G} / \mathrm{A})$ 는 아미노산 코돈에 변화를 주지 않는 synonymous mutation으로 확인되었고 109823T/C은 valine (GTG) 이 alanine (GCG)으로 바뀌는 missence mutation으로 확인되 었다(Table 2).

탐색된 변이지역을 대상으로 유전자형 빈도를 분석한 결과 109737G/A는 GG 유전자형(0.764), GA 유전자형(0.095) 그리 고 AA 유전자형(0.141)을 확인하였다. 109749T/C는 CC 유전 자형(0.179), CT 유전자형(0.101) 그리고 TT 유전자형(0.72)을 확인하였다. 109823T/C는 CC 유전자형(0.171), CT 유전자형 (0.099) 그리고 TT 유전자형(0.73)을 확인하였다. $116151 \mathrm{G} / \mathrm{A}$ 는 GG 유전자형(0.417), GA 유전자형(0.214) 그리고 AA 유전 자형(0.369)을 확인하였다. 109926G/A는 GG 유전자형(0.857), $\mathrm{GA}$ 유전자형(0.036) 그리고 $\mathrm{AA}$ 유전자형(0.107)을 확인하였 다(Table 3). 


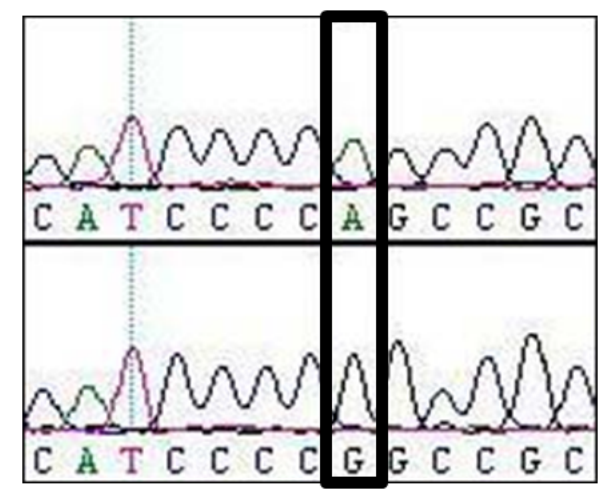

109737G/A

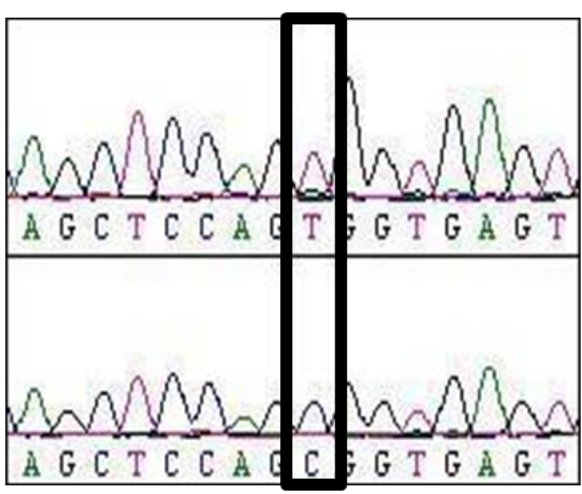

109823T/C

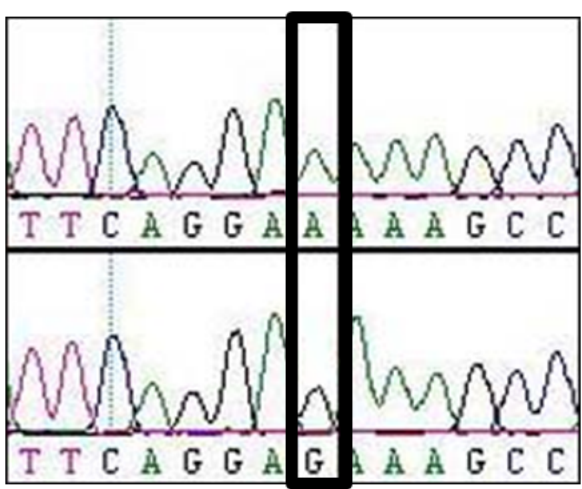

116151G/A

Table 2. The identified SNPs of bovine CAST gene in this study

\begin{tabular}{ccc}
\hline SNP position & Amino acid change & Location \\
\hline $109737 G / A$ & Proline $\rightarrow$ Proline & Exon20 \\
109749T/C & Proline $\rightarrow$ Proline & Exon20 \\
109823T/C & Valine $\rightarrow$ Alanine & Exon20 \\
109926G/A & - & Intron \\
116151G/A & Glutamicacid $\rightarrow$ Glutamicacid & Exon22 \\
\hline
\end{tabular}

\section{한우집단에서 $C A S T$ 유전자변이의 연관불균형 분석}

한우집단 내에서 탐색된 총 5 개의 $\mathrm{SNP}$ 를 대상으로 연관불 균형(LD, Linkage disequilibrium) 분석을 수행하여 Table 4에 각 $\mathrm{SNP}$ 간의 $\mathrm{D}^{\prime}$ 값과 r-square 값을 제시하였고, $\mathrm{SNP}$ 간의

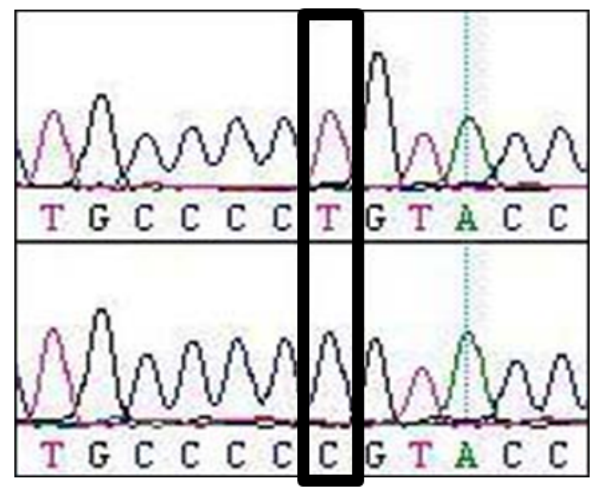

109749T/C

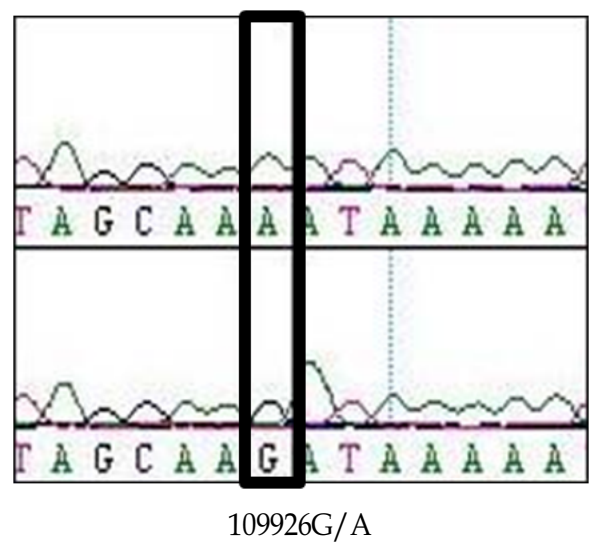

Fig. 1. Sequence analysis of polymorphic sites within exon 20, exon 22 and intron 20 located in the bovine CAST gene. r-square 값을 도식화하여 Fig. 2에 제시하였다. 109737G/A, $109749 \mathrm{~T} / \mathrm{C}, 109823 \mathrm{~T} / \mathrm{C}$ 그리고 109926G/A 변이들 간의 $\mathrm{D}^{\prime}$ 값의 경우 1에서 0.975로 나타났으며, r-square 값은 0.932-0.51 로 확인되어 비교적 강한 LD가 형성되어 있음을 확인하였다. G116150 변이지역의 경우 다른 4 개의 변이지역(109737G/A, $109749 \mathrm{~T} / \mathrm{C}, 109823 \mathrm{~T} / \mathrm{C}, 109926 \mathrm{G} / \mathrm{A}$ )들과의 $\mathrm{D}^{\prime}$ 값이 0.4020.425 로 나타났으며 r-square 값은 $0.072-0.038$ 로 확인되었다.

\section{한우집단에서 $C A S T$ 유전자 내 SNP와 경제형질 간의 연} 관성 분석

변이들 간의 연관 불평형 $(\mathrm{LD})$ 정도가 가장 낮은 수준에 있 는 2개의 변이지역(109926G/A와 $\left.116151 \mathrm{G} / \mathrm{A}, \mathrm{r}^{2}=0.038\right)$ 을 대 
Table 3. Distribution of genotypes and alleles for bovine CAST gene in this study

\begin{tabular}{|c|c|c|c|c|}
\hline SNP position & \multicolumn{2}{|c|}{ Genotype frequency } & \multicolumn{2}{|c|}{ Allele frequency } \\
\hline \multirow{3}{*}{ 109737G/A } & GG & 0.764 & \multirow{3}{*}{$\begin{array}{l}\mathrm{G} \\
\mathrm{A}\end{array}$} & \multirow{3}{*}{$\begin{array}{l}0.811 \\
0.189\end{array}$} \\
\hline & GA & 0.095 & & \\
\hline & $\mathrm{AA}$ & 0.141 & & \\
\hline \multirow{3}{*}{ 109749T/C } & $\mathrm{CC}$ & 0.179 & \multirow{3}{*}{$\begin{array}{l}\mathrm{C} \\
\mathrm{T}\end{array}$} & \multirow{3}{*}{$\begin{array}{l}0.232 \\
0.768\end{array}$} \\
\hline & CT & 0.101 & & \\
\hline & TT & 0.72 & & \\
\hline \multirow{3}{*}{ 109823T/C } & $\mathrm{CC}$ & 0.171 & \multirow{3}{*}{$\begin{array}{l}\mathrm{C} \\
\mathrm{T}\end{array}$} & \multirow{3}{*}{$\begin{array}{l}0.22 \\
0.78\end{array}$} \\
\hline & CT & 0.099 & & \\
\hline & $\mathrm{TT}$ & 0.73 & & \\
\hline \multirow{3}{*}{ 109926G/A } & GG & 0.857 & \multirow{3}{*}{$\begin{array}{l}\mathrm{G} \\
\mathrm{A}\end{array}$} & \multirow{3}{*}{$\begin{array}{l}0.875 \\
0.125\end{array}$} \\
\hline & GA & 0.036 & & \\
\hline & $\mathrm{AA}$ & 0.107 & & \\
\hline \multirow{3}{*}{ 116151G/A } & GG & 0.417 & \multirow{3}{*}{$\begin{array}{l}\mathrm{G} \\
\mathrm{A}\end{array}$} & \multirow{3}{*}{$\begin{array}{l}0.524 \\
0.476\end{array}$} \\
\hline & GA & 0.214 & & \\
\hline & AA & 0.369 & & \\
\hline
\end{tabular}

상으로 경제형질과의 연관성 분석을 실시하였다.

CAST 유전자의 2 개의 변이지역과 경제형질간의 연관성을 분석한 결과 등심단면적(109926G/A, $\mathrm{p}<0.05)$ 과 18 개월령 체중 (116151G/A, p<0.05)에서 유의적인 연관성이 검출 되었다.

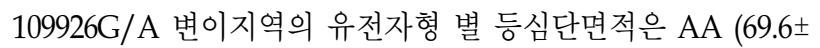

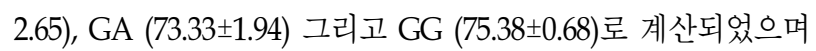
$\mathrm{AA}$ 유전자형과 $\mathrm{GG}$ 유전자형간의 차이가 유의적인 $(\mathrm{p}<0.05)$ 것
으로 확인 되었다(Table 5). 또한 116151G/A 변이지역은 18개

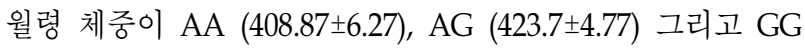
(428.54 \pm 4.49$)$ 로 계산되었으며 $\mathrm{AA}$ 유전자형과 $\mathrm{GG}$ 유전자형 간 의 차이가 유의적인 $(\mathrm{p}<0.05)$ 것으로 확인 되었다(Table 6).

근육 량은 정상적으로 단백질의 합성과 분해가 균형을 이루 어 일정하게 유지된다. 그러나 단백질의 분해가 증가하거나 합성이 감소하는 상황은 세포의 성장과 노화에 크게 영향을 미치게 된다. 성장호르몬의 단백질 대사작용은 동화작용을 가 져 단백질 합성을 증가시켜 근육 용적의 증가에 영향을 미친 다[10,11,19]. 또한 단백질의 분해의 경우 지금까지 밝혀진 기 전으로는 ubiquitin-proteasome 경로와 calpain-calpastatin계, NF-kB와 같은 전사인자의 발현, 세포사멸(apoptosis), autophagy-lysosome 경로 등이 있다[9,12,16-18,23,24,29]. 골격 근의 성장속도의 증가는 결론적으로 근단백질 분해가 감소하 기 때문이며 이는 calpain 시스템의 활성도의 감소와 연관이 있으며 calpastatin의 활성도의 큰 증가로 인해 감소가 이루어 진다[14]. 최근 Schenkel 등[30]의 보고에 따르면 육우를 대상 으로 CAST SNP와 고기의 연도 및 도체형질과의 연관성을 분석하였다. 분석된 $\mathrm{SNP}(\mathrm{G} / \mathrm{C})$ 는 exon5와 6번 지역 사이에 있는 intron 지역에 위치하고 있으며 C 대립유전자는 고기의 연도를 증가 시키는 반면 등심의 크기가 감소되고 지방양의 증가에 유의적인 연관성을 보고하였다. 또한 돼지의 CAST 유 전자 내 변이를 분석한 결과 등지방 두께와 등심단면적에서 유의적인 연관성이 확인되었다[22]. 따라서 CAST유전자는 도

Table 4. Linkage disequilibrium (LD) among polymorphisms in bovine CAST gene

\begin{tabular}{|c|c|c|c|c|c|c|}
\hline & & \multicolumn{5}{|c|}{$\mathrm{D}^{\prime}$} \\
\hline & & 109737G/A & 109749T/C & 109823T/C & 109926G/A & 116151G/A \\
\hline \multirow{5}{*}{$r^{2}$} & 109737G/A & - & 1.000 & 0.975 & 1.000 & 0.421 \\
\hline & 109749T/C & 0.932 & - & 0.977 & 1.000 & 0.422 \\
\hline & 109823T/C & 0.866 & 0.932 & - & 1.000 & 0.402 \\
\hline & 109926G/A & 0.560 & 0.522 & 0.510 & - & 0.425 \\
\hline & 116151G/A & 0.067 & 0.072 & 0.067 & 0.038 & - \\
\hline
\end{tabular}

Table 5. Least squares means and standard errors for economic traits of 109926G/A genotype in bovine CAST gene

\begin{tabular}{cccc}
\hline & & $109926 \mathrm{G} / \mathrm{A}$ & GG \\
\cline { 2 - 4 } LW & AA & GA & $543.0 \pm 4.86$ \\
CW & $537.33 \pm 13.74$ & $560.0 \pm 23.81$ & $315.58 \pm 3.08$ \\
LMA & $312.8 \pm 8.72$ & $318.6 \pm 15.1$ & $75.38 \pm 0.68^{\mathrm{b}}$ \\
BF & $69.6 \pm 2.65^{\mathrm{a}}$ & $73.33 \pm 1.94^{\mathrm{ab}}$ & $0.84 \pm 0.03$ \\
MS & $0.86 \pm 0.08$ & $0.96 \pm 0.15$ & $1.80 \pm 0.1$ \\
W6 & $1.53 \pm 0.29$ & $1.20 \pm 0.5$ & $161.42 \pm 2.44$ \\
W12 & $159.19 \pm 6.86$ & $169.9 \pm 9.89$ & $276.05 \pm 3.15$ \\
W18 & $274.41 \pm 8.9$ & $283.17 \pm 15.42$ & $420.56 \pm 3.77$ \\
W24 & $422.45 \pm 10.67$ & $426.29 \pm 15.48$ & $577.53 \pm 5.62$ \\
\hline
\end{tabular}

LW: Live Weight, CW: Carcass Weight, LMA: Longissimus Muscle Area, BF: Backfat Thickness, MS: Marbling Score, W6: Weight at 6 months, W12: Weight at 12 months, W18: Weight at 18 months, W24: Weight at 24 months, ${ }^{\text {a }},{ }^{\text {b }}$ : Different superscripts within row are significantly differ $(p<0.05)$. 
Table 6. Least squares means and standard errors for economic traits of 116151G/A genotype in bovine CAST gene

\begin{tabular}{cccc}
\hline & & $116151 \mathrm{G} / \mathrm{A}$ & GG \\
\cline { 2 - 3 } LW & AA & GA & $547.31 \pm 5.91$ \\
CW & $550.29 \pm 6.29$ & $530.0 \pm 8.26$ & $319.12 \pm 3.78$ \\
LMA & $319.87 \pm 4.02$ & $308.53 \pm 5.28$ & $74.99 \pm 0.85$ \\
BF & $75.33 \pm 0.9$ & $74.6 \pm 1.18$ & $0.86 \pm 0.04$ \\
MS & $0.87 \pm 0.04$ & $0.80 \pm 0.05$ & $1.76 \pm 0.13$ \\
W6 & $1.94 \pm 0.14$ & $1.6 \pm 0.18$ & $159.46 \pm 2.91$ \\
W12 & $160.58 \pm 3.14$ & $158.07 \pm 4.06$ & $277.88 \pm 3.87$ \\
W18 & $274.14 \pm 5.41$ & $277.47 \pm 4.12$ & $428.54 \pm 4.49^{\mathrm{b}}$ \\
W24 & $408.87 \pm 6.27^{\mathrm{a}}$ & $423.7 \pm 4.77^{\mathrm{ab}}$ & $586.15 \pm 6.78$
\end{tabular}

LW: Live Weight, CW: Carcass Weight, LMA: Longissimus Muscle Area, BF: Backfat Thickness, MS: Marbling Score, W6: Weight at 6 months, W12: Weight at 12 months, W18: Weight at 18 months, W24: Weight at 24 months, a , b: Different superscripts within row are significantly differ $(p<0.05)$.

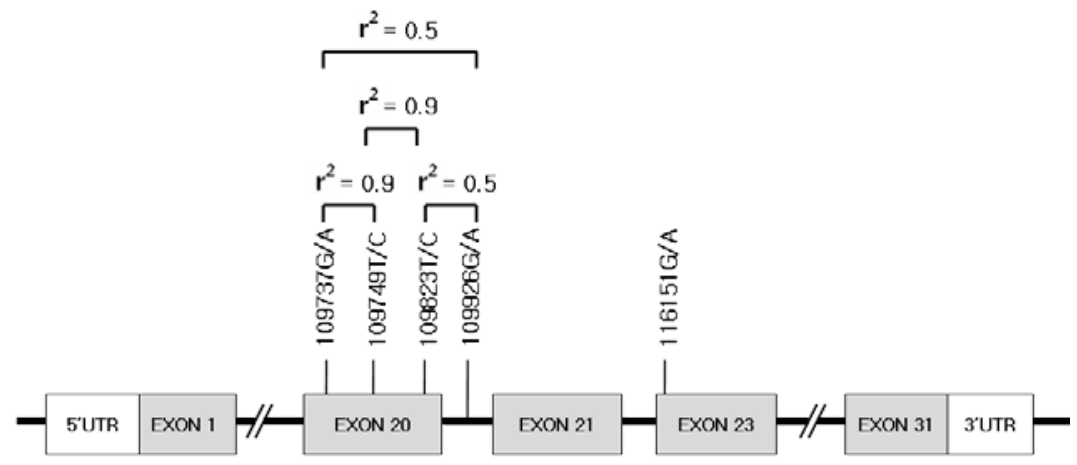

Fig. 2. SNP detection and Linkage disequilibrium of bovine CAST gene on BTA 7(Gene Bank accession no. NC_007305). Coding exons are marked by shaded blocks and $5^{\prime}$ and $3^{\prime}$ UTR by white blocks.

축 후 숙성과정에서 고기의 연도를 증가시키는데 영향을 미칠 뿐만 아니라 가축의 성장에도 깊은 연관성이 있으며, 본 연구 를 통해 새롭게 발견된 SNP 중 109926G/A와 116151G/A는 한우의 등심단면적과 18 개월령 체중에서 유의적인 연관성을 확인하였다. 하지만 $109926 \mathrm{G} / \mathrm{A}$ 은 intron에 위치하고 있으며 $116151 \mathrm{G} / \mathrm{A}$ 의 경우 exon 지역에 위치하고 있지만 아미노산 서열에 영향을 주지 못하는 synonymous mutation으로 확인 되어 두 변이 모두는 유전자의 기능에 직접적인 영향을 미치 지 못할 것으로 사료되지만 유전자의 regulatory region에 존 재하는 변이 또는 다른 주유전자의 변이들과 연관되어 형질에 미치는 유전자의 변이 효과가 유인적으로 확인된 것으로 추정 된다. 따라서 CAST 유전자는 고기의 연도 이외에도 성장과 관련된 후보유전자로서의 활용 가능성이 높을 것으로 판단되 며 추후 추가적인 연구를 통해 성장 관련 형질을 개량하기 위한 분자 표지 개발이 가능할 것으로 사료된다.

\section{감사의 글}

본 연구는 국립 부산 대학교 연구 과제를 2년 동안 지원
받아 진행되었습니다.

\section{References}

1. Balcerzak, D., S. Poussard, J. J. Brutis, N. Flamrani, M. Soriano, P. Cottin, and A. Ducastaing. 1995. An antisense oligonucleotide to m-calpain mRNA inhibits myoblast fusion. J. Cell Sci. 108, 2077-2082.

2. Barnoy, S., T. Glasre, and N. S. Kosower. 1997. Calpain and calpastatin in myoblast defferentiation and fusion effects of inhibitors. Biochim. Biophys. Acta 1358, 181-188.

3. Bishop, M. D., J. Koohmaraie, J. Killefer, and S. Kappes. 1993. Rapid communication: restriction fragment length polymorphisms in the bovine calpastatin Gene. J. Anim. Sci. 71, 2277.

4. Cheong, H. S., D. Yoon, L. H. Kim, B. L. Park, H. W. Lee, C. S. Han, E. M. Kim, H. Cho, E. R. Chung, I. Cheong, and H. D. Shin. 2007. Titin-cap (TCAP) polymorphisms associated with marbling score of beef. Meat Sci. 77, 257-263.

5. Cho, S., T. S. Park, D. Yoon, H. S. Cheong, S. Namgoong, B. L. Park, H. W. Lee, C. S. Han, E. M. Kim, I. C. Cheong, H. Kim, and H. D. Shin. 2008. Identification of genetic poly- 
morphisms in FABP3 and FABP4 and putative association with back fat thickness in Korean native cattle. BMB. Rep. 41, 29-34.

6. Chung, H. Y., M. E. Davis, and H. C. Hines. 1999. A DNA polymorphism of the bovine calpastatin gene detected by SSCP analysis. Anim. Genet. 30, 80.

7. Chung, H. Y., M. E. Davis, and H. C. Hines. 2001. Genetic variants detected by PCR-RFLP in intron 6 of the bovine calpastatin gene. Anim. Genet. 32, 53.

8. Cockett, N. E., T. L. Shay, R. D. Green, and D. L. Hancock. 1995. Rapid communication: a TaqI restriction fragment length polymorphism in the bovine calpastatin gene. $J$. Anim. Sci. 73, 3790.

9. Cote, C. G. and B. R. Celli. 2007. Predictors of mortality in chronic obstructive pulmonary disease. Clin. Chest Med. 28, 515-524.

10. Cuneo, R. C., F. Salomon, C. M. Wiles, and P. H. Sonksen. 1990. Skeletal muscle performance in adults with growth hormone deficiency. Horm. Res. 33, 55-60.

11. Cuneo, R. C., F. Salomon, C. M. Wiles, J. M. Round, R. Hesp, and P. H. Sonksen. 1992. Histology of skeletal muscle in adults with growth hormone deficiency: Comparison with normal muscle and response to growth hormone treatment. Horm. Res. 37, 23-28.

12. Garrouste-Orgeas, M., G. Troche, E. Azoulay, A. Caubel, A. de Lassence, and C. Cheval. 2004. Body mass index. An additional prognostic factor in ICU patients. Intensive Care Med. 30, 437-443.

13. Geesink, G. H. and M. Koohmaraie. 1999. Effect of calpastatin on degradation of myofibrillar proteins by mu-calpain under postmortem conditions. J. Anim. Sci. 77, 2685-2692.

14. Goll, D. E., V. F. Thompson, R. G. Taylor, and A. Ouali. 1998. The calpain system and skeletal muscle growth. Canadian J. Anim. Sci. 78, 503-512.

15. Ha, O. K., J. S. Choi, S. W. Kim, Y. I. Choi, S. S. Lee, J. W. Choi, S. H. Jeon, and K. S. Kim. 2009. Commercial Application of Porcine MC1R Gene Polymorphisms to Korean Pork Industry. J. Anim. Sci. \& Technol. (Korean) 51, 193-200.

16. Hasselgren, P. O., M. J. Menconi, M. U. Fareed, H. Yang, W. Wei, and A. Evenson. 2005. Novel aspects on the regulation of muscle wasting in sepsis. Int J. Biochem. Cell Biol. 37, 2156-2168.

17. Hund, E. F. 1996. Neuromuscular complications in the ICU: the spectrum of critical illness-related conditions causing muscular weakness and weaning failure. J. Neurol. Sci. 136, 10-16.

18. Hund, E. 2001. Neurological complications of sepsis: critical illness polyneuropathy and myopathy. J. Neurol. 248, 929934.
19. Jorgensen, J. O. L., S. A. Pedersen, L. Thuesen, J. Jorgensen, T. Ingemann-Hansen, and N. E. Shakkebaek. 1989. Beneficial effects of growth hormone treatment in growth hormone deficient adults. Lancet 1, 1221-1225.

20. Juszczuk-Kubiak, E., T. Sakowski, K. Flisikowski, K. Wicinska, J. Oprzadek, and S. J. Rosochacki. 2004. Bovine mu-calpain (CAPN1) gene: new SNP within intron 14. J. Appl. Genet. 45, 457-460.

21. Kong, H. S., J. D. Oh, J. H. Lee, D. H. Yoon, Y. H. Choi, B. W. Cho, H. K. Lee, and G. J. Jeon. 2007. Association of sequence variations in DGAT 1 gene with economic traits in Hanwoo (Korea cattle). Asian-Aust. J. Anim. Sci. 20, 817-820.

22. Kurył, J., W. Kapelanki, M. Pierzchała, S. Grajewska2, and M. Bocian. 2003. Preliminary observations on the effect of calpastatin gene (CAST) polymorphism on carcass traits in pigs. Anim. Sci. Papers and Reports 2, 87-95.

23. Kutner, N. G. and R. Zhang. 2001. Body mass index as a predictor of continued survival in older chronic dialysis patients. Int. Urol. Nephrol. 32, 441-448.

24. Lang, C. H., R. A. Frost, and T. C. Vary. 2007. Regulation of muscle protein synthesis during sepsis and inflammation. Am. J. Physiol. Endocrinol. Metab. 293, E453-459.

25. Lee, H. J., S. H. Lee, Y. M. Cho, H. B. Yoon, B. K. Jeon, S. J. Oh, M. S. Kwon, and D. H. Yoon. 2004. Association Between the Polymorphism on Intron 5 of the Lipoprotein Lipase Gene and Carcass Traits in Hanwoo (Korean cattle). J. Anim. Sci. \& Technol. (Korean) 46, 947-956.

26. Lonergan, S. M., C. W. Ernst, M. D. Bishop, C. R. Calkins, and M. Koohmaraie. 1995. Relationship of restriction fragment length polymorphisms (RFLP) at the bovine calpastatin locus to calpastatin activity and meat tenderness. J. Anim. Sci. 73, 3608-3612.

27. Mellegren, R. L. 1997. Evidence for participation of a calpain-like cysteine protease in cell progression through the late G1 phase. Biochemical and Biophysical Research Communications 236, 555-558.

28. Nonneman, D., S. M. Kappes, and M. Koohmaraie. 1999. Rapid communication: a polymorphic microsatellite in the promoter region of the bovine calpastatin gene. J. Anim. Sci. 77, 3114-3115.

29. Oreopoulos, A., R. Padwal, K. Kalantar-Zadeh, G. C. Fonarow, C. M. Norris, and F. A. McAlister. 2008. Body mass index and mortality in heart failure: a meta-analysis. Am. Heart J. 156, 13-22.

30. Schenkel, F. S., S. P. Miller, Z. Jiang, I. B. Mandell, X. Ye, H. Li, and J. W. Wilton. 2006. Association of a single nucleotide polymorphism in the calpastatin gene with carcass and meat quality traits of beef cattle. J. Anim. Sci. 84, 291-299. 


\section{초록 : 한우(Bos taurus coreanae)의 CAST 유전자 내 변이지역 탐색 및 경제형질과의 연관성 분석}

오재돈 · 이진아 · 이건우 · 박경도 · 조병욱 · 전광주 · 이학교 · 공홍식*

(한경대학교 유전정보연구소, ${ }^{1}$ 부산대학교 생명자원과학대학)

Calpastatin (CAST)은 calpain의 억제제 역할을 하는 유전자이며 BTA7에 위치하고 있다. Calpain을 억제하는 CAST 유전자 내 다형성이 육질의 연도에 영향을 미치고 있는 것이 알려져 있다. 또한 여러 연구를 통해 calpain 시스템은 일반 골격근의 성장에 중요한 역할을 하는 것으로 보고되었다. 따라서 본 연구는 한우 집단의 CAST 유전자 내 변이 지역을 탐색하여 경제형질과의 연관성을 분석하기 위하여 실시하였다. CAST 유전자(Accession no. NC_007305) 단일염기변이지역을 탐색 결과 총 5개의 변이(109749T/C, 116151G/A, 109737G/A, 109823T/C, $109926 \mathrm{G} / \mathrm{A}$ ) 지역이 탐색 NCBI에 등록되어 있지 않은 새로운 변이로 본 연구를 통해 탐색되었다. 한우집단 내에 서 탐색된 총 5 개의 SNP를 대상으로 연관불균형(LD, Linkage disequilibrium) 분석을 수행하였다. 변이들 간의 연관불균형 $(\mathrm{LD})$ 정도가 가장 낮은 수준에 있는 2 개의 변이지역(109926G/A와 $116151 \mathrm{G} / \mathrm{A}, \mathrm{r}^{2}=0.038$ )을 대상으로 경제형질과의 연관성 분석을 실시한 결과 등심단면적(109926G/A, $\mathrm{p}<0.05)$ 과 18 개월령 체중(116151G/A, $\mathrm{p}<0.05)$ 에서 유의적인 연관성이 검출 되었다. CAST유전자는 도축 후 숙성과정에서 고기의 연도를 증가시키는데 영향을 미칠 뿐만 아니라 가축의 성장에도 깊은 연관성이 있으며, 본 연구를 통해 CAST 유전자 내 변이는 성장 관련 형질과의 연관성이 유의적인 것으로 확인되었다. 